\title{
Structure and tree species composition of forest fringe of a forest fragment in an oil palm plantation at Suai, Sarawak, Malaysian Borneo
}

\author{
CLAUDIA LENNYA JANA, ISMAIL JUSOH ${ }^{*}$ \\ Faculty of Resource Science and Technology, Universiti Malaysia Sarawak, 94300 Kota Samarahan, Sarawak, Malaysia \\ Tel.: +60-82-582990, Fax.: +60-82-583160, ’email: jismail@unimas.my
}

Manuscript received: 31 May 2021. Revision accepted: 28 June 2021

\begin{abstract}
Jana CL, Jusoh I. 2021. Structure and tree species composition of forest fringe of a forest fragment in an oil palm plantation at Suai, Sarawak, Malaysian Borne. Biodiversitas 22: 3013-3019. Forest fragments in oil palm plantations are remnants of the original forest tract with various sizes and shapes after clearing forested lands for crops and roads. Fragmented forests usually created forest fringe or edge habitats that differ in light intensity, temperature, humidity, heavy rainfall, and strong winds from its core. The study was aimed to determine the structure and tree species composition of the forest fringe of a fragmented forest in an oil palm plantation Suai, Sarawak. This study established a total of 24 sampling plots within the forest fringe. Tree enumeration and species identification were conducted in all sampling plots to all trees with a diameter at breast height $5 \mathrm{~cm}$ and higher. A total of 59 families comprised of 274 species and 948 trees individuals were recorded. The aboveground biomass stand at $260 \mathrm{Mg} \mathrm{ha}^{-1}$. Species Elateriospermum tapos was predominant, and family Dipterocarpaceace dominated the forest fringe. Based on the calculated indices, species diversity and richness were considered high, while the dispersion of individual trees was random but unevenly distributed. Natural regeneration in the forest fringe is sustainable. The forest structure and species composition are intact, and without significant disturbance, the whole forest fragment is self-sustain.
\end{abstract}

Keywords: Disturbance, forest edge, forest remnants, natural regeneration, species diversity

\section{INTRODUCTION}

Forest fragments of different sizes and shapes are common in oil palm plantations. It occurs during the plantation establishment phase, where it causes biodiversity loss (Shevade and Loboda 2019). The process starts with timber harvesting of primary or secondary forests, subsequently clear-felled most forested areas for oil palm plantation and roads, leaving scattered tracts of standing trees (Bakewell and Donysius 2014). According to Haddad et al. (2015), this forest fragmentation process is considered a major threat to biodiversity. Many oil palm plantation companies have gazetted the forest fragments as High Conservation Value (HCV) forests to support the conservation initiatives.

Generally, large forest fragments contain a relatively uniform core that provides sufficient conditions for tree communities to sustain themselves (Patrício et al. 2019). However, as fragments, original areas of natural habitat have cleared, the impacts on tree diversity and forest sustainability remain unknown. The edge effect could adversely affect the core areas, especially when the ratio of edge habitat to core habitat is significant as in linear-shape fragments. Many species naturally occur in the core habitat. They cannot survive near the edges of the habitat due to unfavorable conditions like light levels, temperature, humidity, and susceptibility to wind disruption. Destruction and alteration of habitat due to forest fragmentation is the most significant single threat to biological diversity worldwide (Mullu et al. 2016). It caused a loss in
Cypripedium calceolus population (Orchidaceae) in the Adamello-Brenta Natural Park, North Italy (Perazza and Decarli 2020), increased in mortality of large trees (Bulafu et al. 2013), and high degradation of the population tree structure and regeneration (Gebeyehu et al. 2019).

Some birds are sensitive to increased wind, sunlight intensity, and air temperature to avoid nesting in an edge habitat (Laurance et al. 2011). A shift in bird species may occur due to environmental change in forest habitat, which may jeopardize the balance of avifauna communities and increase their vulnerability (Simanov and Matantseva 2020). Forest fringe can be the significant factor contributing to the reduced distribution and abundance of wildlife species attributed to proximity to the road that increased the risk of mortality due to roadkill and other anthropogenic pressure (Mohd-Azlan et al. 2020). There is an increase of human-bear conflict in the areas within a three-kilometer buffer between forest edge and settlements (Letro et al. 2020).

Fragmentation consequentially causes the creation of fringe or edge habitats. Forest fringe or forest edge is 100 $\mathrm{m}$ from the edge towards the interior of a fragmented forest (Aragón et al. 2015). This form of the belt up to $100 \mathrm{~m}$ in width bordering the fragmented forest with open vegetation outside forest fragments results in distinct microclimate differences compared with the core or interior forest. Altered microclimatic conditions may benefit invasive, pioneer, and weedy species (Mullu 2016).

Alien plants can be host to pests and diseases transmitted to forest fragments, affecting the survival of 
native species (Prospero and Cleary 2017). This may cause a decline in forest species and risking the sustainability of the forest. Forest edge effects have been shown to increase the mortality of tree canopy (Mullu 2016), creating more gaps, increased light penetration, alter forest regeneration and eventually affect vegetation structure and composition of the forest fringe (Ordway and Asner 2020). Forest gaps and alteration of the microclimate will permanently interfere with the natural tree regeneration causing a shift in the species composition and forest structure (Aragón et al. 2015). The survival rate, growth, low tree density, and biomass increase in liana and vine in the forest fringe result in overall floristics trajectory changes (Campbell et al. 2018).

This study analyzes the forest fringe communities of a forest fragment in an oil palm plantation. Specifically, we investigate the dominant species, tree density, tree density pattern, and aboveground biomass. It is essential to understand the status of tree communities because of the changing environment. Understanding the impacts of edge effects on the forest fringe community structure and tree composition will provide sound judgment on managing and conserving the fragmented forest. Species composition is an important indicator of ecological and management processes at a site. It describes the relative contribution of a particular species, and its dominance indicates its ability to thrive in the forest edge environment. Environmental variables such as rainfall and temperature affect the species richness within the forest (Martinez-Camilo et al. 2018). Soil properties, namely $\mathrm{pH}$, nitrogen availability and moisture, affected plant distribution (Khapugin 2019). According to Dossa et al. (2013), light intensity and elevation are important in plant diversity. Vegetation structure identifies the species distribution within a forest stand represented by tree density, basal area, and relative coverage of species in specific size classes (Moss 2012). Species distribution is an important parameter in supporting the diversity of tree species (Pastorella and Paletto 2013) and as an indicator of forest management practices (Ćosović et al. 2020).

Estimating tree biomass is essential for evaluating forest energy, climate change, forest health, and nutrient cycling (Dong et al. 2016). Aboveground biomass (AGB) is vital for carbon storage in trees and is used to study carbon sequestration (Ravindranath and Ostwald 2018). Besides, it is crucial to estimate forest structure and productivity because environmental conditions and site productivity affect the aboveground biomass (Pontes et al. 2019). There are limited studies regarding forest fringe communities in oil palm plantations. Given this in mind, our research aims to determine the stand characteristics and floristics diversity of forest fringe communities of a fragmented forest surrounded by oil palm plantations.

\section{MATERIALS AND METHODS}

\section{Study area}

This study was conducted in an oil palm plantation located at $18 \mathrm{~km}$ of kilometer 115, Bintulu-Miri road, Suai, Miri, Sarawak. The study site is a fragmented forest located at N3 $34^{\prime} 00.76^{\prime \prime}$, E113046'12.72" with an area of approximately 116.28 ha (Figure 1.A and B). The forest type is a lowland mixed dipterocarp forest selectively logged since 1996 and set aside as a high conservation value (HCV) forest. The terrain is undulatingly ranging from 45 to $75 \mathrm{~m}$ a.s.1, receiving 2,890 - $3000 \mathrm{~mm}$ of rainfall throughout the year.

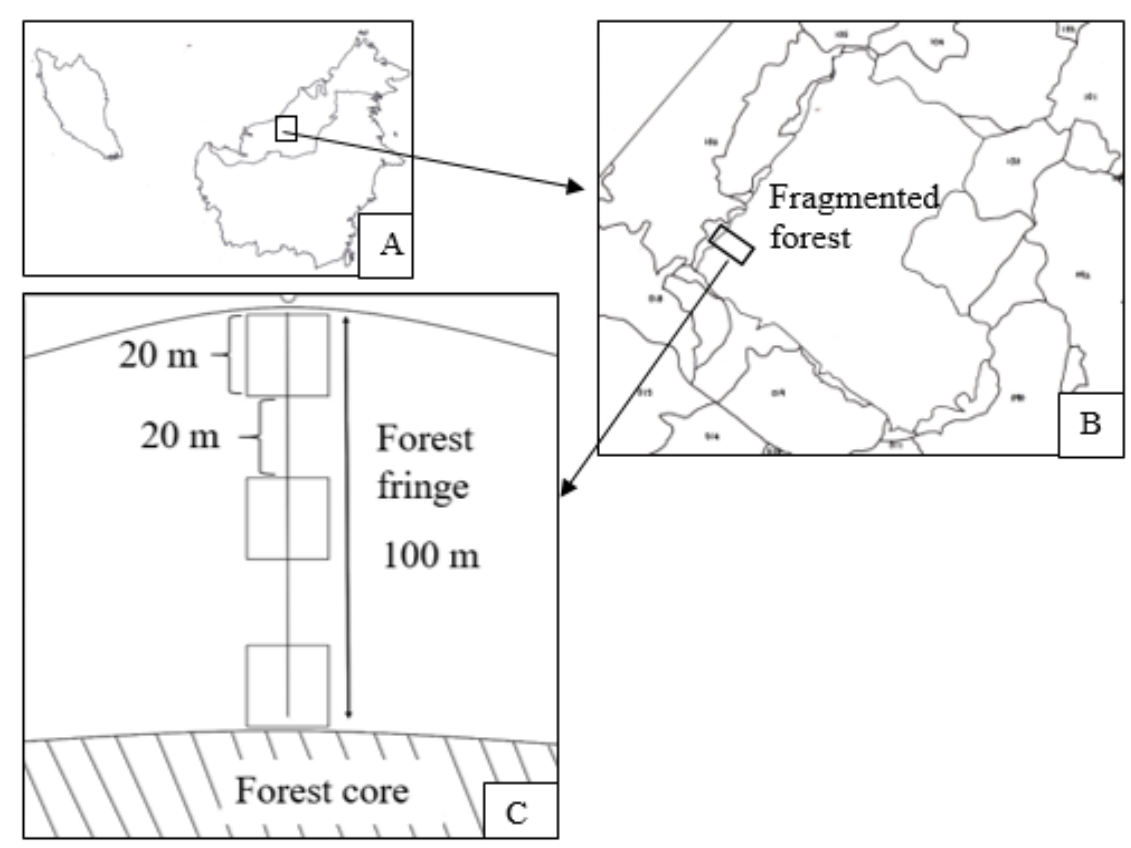

Figure 1. Location of the study area and sampling scheme. A. Relative location of the study area. B. A fragmented forest surrounded by oil palm plantation and position of a transect in the forest fringe. C. Placement of three sampling plots along a transect line within the forest fringe 


\section{Field sampling}

We established eight transects line of $100 \mathrm{~m}$ in length from the forest fringe into the interior of the fragmented forest. Three $20 \times 20 \mathrm{~m}$ sampling plots, each placed $20 \mathrm{~m}$ apart, were constructed along each transect line (Figure 1.C). All trees with a diameter at breast height $(\mathrm{DBH}) \geq 5$ $\mathrm{cm}$ in all sampling plots were enumerated. Measurement of tree diameter over bark at breast height (i.e. $1.30 \mathrm{~m}$ above ground level) was done to the nearest $\mathrm{cm}$ using a diameter tape. Trees with DBH between 5 to $9.9 \mathrm{~cm}$ were classified as saplings. Enumerated trees were preliminarily identified in the field based on bark, slash, and leaves characteristics. Unidentified tree species were named up to the genus level. A detailed species identification was further carried out in UNIMAS herbarium and Forest Department Sarawak herbarium.

\section{Stand structure}

Stand structure was described based on the tree density, basal area, species and family richness, aboveground biomass (AGB), and tree distribution by diameter class. Tree density is the number of trees or tree frequency per unit area. Basal area (BA) of a tree is the term to describe the tree stems occupying an average amount of the area. It is defined as the total cross-sectional area of a number of all stand trees measured at breast height. Aboveground biomass was calculated for each tree using the moist forest AGB equation (Chave et al. 2005).

$$
\begin{gathered}
\mathrm{AGB}=p \times \exp \left(-1.499+2.148 \ln (\mathrm{D})+0.207(\ln (\mathrm{D}))^{2}-0.0281\right. \\
\left.(\ln (\mathrm{D}))^{3}\right)
\end{gathered}
$$

AGB is in dry weight $\left(\mathrm{kg} \mathrm{tree}^{-1}\right), \mathrm{DBH}$ is in $\mathrm{cm}$, and $p$ is basic wood density (in $\mathrm{g} \mathrm{cm}^{-3}$ ). Wood densities of all species were taken from the wood density database at the website of the International Council for Research in Agroforestry (ICRAF). All air-dry wood density (10 - 18\% moisture content) was converted to basic wood density by multiplying wood densities by a value of 0.861 (Vieilledent et al. 2018). The classification of trees by diameter classes illustrates the number of trees present in each diameter class. It indicates the natural regeneration, growth, and mortality of a forest stand (Kacholi 2014).

\section{Species Composition}

Tree species composition was described on the basis of the importance value index (IVI). It was calculated as the sum of relative frequency, relative density and relative coverage (Gebeyehu et al. 2019):

$$
\begin{aligned}
& \text { Relative frequency }(\mathrm{RF})=\frac{\text { Frequency of a species }}{\text { Sum of frequency values of all species }} \times 100 \\
& \text { Relative density }(\mathrm{Rd})=\frac{\text { No. of individuals of a species }}{\text { Total number of individuals of all species }} \times 100 \\
& \text { Relative coverage }(\mathrm{Rba})=\frac{\text { Total basal area of a species }}{\text { Total basal area of all species }} \times 100
\end{aligned}
$$

The family importance value (FIV) was calculated by the summation of the percentages of the three attributes below (Kacholi 2014):

$$
\begin{aligned}
& \text { Relative density (Rde) }=\frac{\text { No. of an individual in a family }}{\text { Total number of trees }} \times 100 \\
& \text { Relative diversity }(\mathrm{RDi})=\frac{\text { No. of species in a family }}{\text { Total no. of species }} \times 100 \\
& \text { Relative dominance (RBDo) }=\frac{\text { Basal area of a family }}{\text { Total basal area }} \times 100
\end{aligned}
$$

Family importance value can be used to analyze each family contribution and indicate the dominance of a particular family in a forest community (Kacholi 2014). Tree species diversity indices, the Shannon-Wiener index of species heterogeneity $\left(H^{\prime}\right)$, Simpson diversity index $(D)$, Pielou's evenness (E) and Margalef $\left(D_{M g}\right)$ species richness and Morisita's index $\left(I_{d}\right)$ of dispersion were calculated based on Magurran (2004). The evenness index ( $\left.E^{\prime}\right)$ value is equal to 1 when the species distribution is perfectly evenly distributed and 0 when the variation is maximum. Morisita index is used to measure the dispersion of plants identify the spatial distribution pattern of the vegetation, whether the population is clustered, random, or dispersedly distributed (Hayes and Castillo 2017). A value of close to 1.0 indicates random dispersion, 0 for uniform and a large number for aggregate distribution.

\section{RESULTS AND DISCUSSION}

\section{Stand structure}

A total of 948 trees representing 59 families comprised of 137 genera and 274 species were recorded in the 24 plots ( 0.96 ha in sum) (Table 1$)$. A recent study conducted in the forest core or interior of the same forest fragmented

\begin{tabular}{|c|c|}
\hline Variable & Value \\
\hline Number of trees $(\mathrm{DBH} \geq 5 \mathrm{~cm})$ & 948 \\
\hline Number of trees $(\mathrm{DBH} \geq 10 \mathrm{~cm})$ & 585 \\
\hline Number of species & 274 \\
\hline Number of genera & 137 \\
\hline Number of families & 59 \\
\hline Mean basal area $\left(\mathrm{m}^{2} \mathrm{ha}^{-1}\right)(\mathrm{DBH} \geq 5 \mathrm{~cm})$ & 29.9 \\
\hline Mean basal area $\left(\mathrm{m}^{2} \mathrm{ha}^{-1}\right)(\mathrm{DBH} \geq 10 \mathrm{~cm})$ & 26.3 \\
\hline Mean aboveground biomass $\left(\mathrm{Mg} \mathrm{ha}^{-1}\right)(\mathrm{DBH} \geq 5 \mathrm{~cm})$ & 260 \\
\hline Mean aboveground biomass $\left(\mathrm{Mg} \mathrm{ha}^{-1}\right)(\mathrm{DBH} \geq 10 \mathrm{~cm})$ & 249 \\
\hline
\end{tabular}
recorded 1367 tree ha ${ }^{-1}$, a basal area of $34.3 \mathrm{~m}^{2} \mathrm{ha}^{-1}, 55$ families, 127 genera and 287 species (Jusoh 2017). By comparison, the forest core tree stocking is denser in the forest core, but the family, genera and species richness were comparable.

Table 1. Structural characteristics of forest fringe of a fragmented forest in 24 plots of $20 \times 20 \mathrm{~m}$ in an oil palm plantation 
Tree density of 585 tree ha $^{-1}$ with $\mathrm{DBH} \geq 10 \mathrm{~cm}$ recorded in this study was much lower compared to 710 and 718 tree $\mathrm{ha}^{-1}$, as recorded by Ling and Julia (2012) and Vilma et al. (2012), respectively. Since the later three studies were conducted in the forest core of National Park and Conservation Area in Sarawak, higher tree densities are expected.

Diameter size distribution showed that smaller trees are in abundance, and the number of trees decreased with diameter size (Figure 2). This distribution is known as the inverted-J or reverse-J curve (Pontes et al. 2019). About $38.3 \%$ of the enumerated tree are sapling, and another $38.6 \%$ are pole size trees $(10.1-20 \mathrm{~cm} \mathrm{DBH})$, making about $77 \%$ of the forest fringe tree small. About $4.5 \%$ of trees were considered big size $(\mathrm{DBH} \geq 40 \mathrm{~cm})$. The inverted-J curve illustrates that tree saplings count is high, and the number of tree declines in the upper diameter classes indicates that forest recruitment or regeneration is good. It's a typical structure in tropical forests, and the natural regeneration will be successful (Kacholi 2014). The distribution pattern of decrease in the number of trees with the increase of trees diameter class agrees with other reports (Ling and Julia 2012; Jusoh 2017; Dar et al. 2019). The curve is smoother for the smaller diameter class because the trees were less dense in the large diameter class. It also indicates that the number of trees between successive classes was smaller in the larger diameter class than those found in the smaller diameter class.

The basal area (BA) in the forest fringe with $\mathrm{DBH} \geq 10$ $\mathrm{cm}$ was low $\left(26.3 \mathrm{~m}^{2} \mathrm{ha}^{-1}\right)$ compared to the forest core. A previous study reported that the BA of the forest core was $31.9 \mathrm{~m}^{2} \mathrm{ha}^{-1}$ (Jusoh 2017). The low basal area is attributed to the small diameter of trees in the forest fringe. Ling and Julia (2012) recorded $43.0 \mathrm{~m}^{2} \mathrm{ha}^{-1}$ for the Semenggoh Arboretum Sarawak forest core.

The total biomass of trees was $260 \mathrm{Mg} \mathrm{ha}^{-1}$. The forest fringe stored the bulk (39\%) of the total AGB in the smaller diameter (DBH 5 to $30 \mathrm{~cm})$. The large trees $(\mathrm{DBH}$

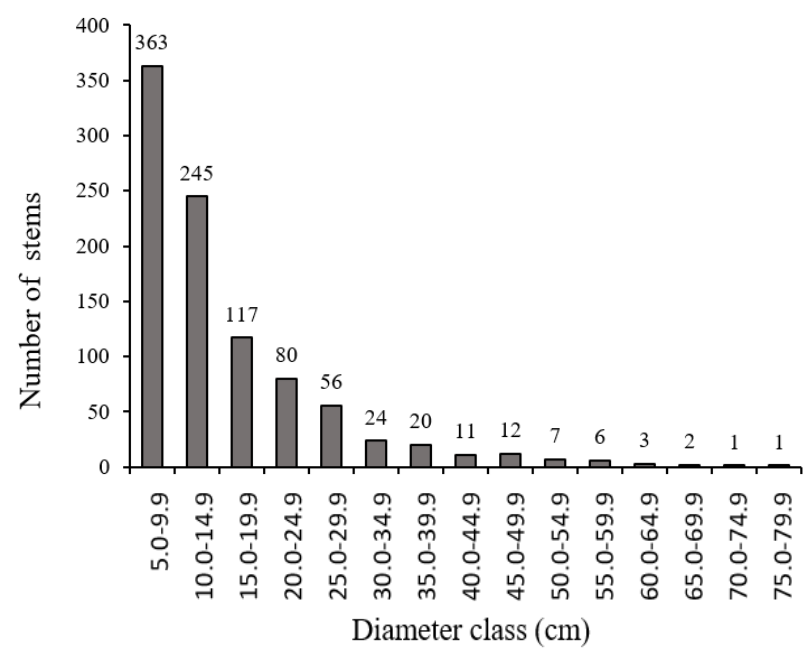

Figure 2. Diameter distribution of all trees species in the forest fringe $\geq 50 \mathrm{~cm}$ ) stored $29 \%$, and the medium-size tree makes up the rest of the total AGB. There were 861 small trees compared to only 20 large trees reflecting a strong positive association between trees diameter and aboveground biomass distribution. The increasing trend of AGB in the smaller diameter trees and the cumulative increased in total aboveground biomass (Figure 3) is typical for the tropical forest of Southeast Asia, Central, Western and Eastern Africa, and South America (Feldpausch et al. 2012).

The AGB of tropical forest was estimated to be $418 \pm$ $112.9 \mathrm{Mg} \mathrm{ha}^{-1}$ (mean \pm standard deviation) based on studies done in 120 sites in Southeast Asia, Africa and South America (Slik et al. 2013). The low tree density and very few large-diameter trees affect the low AGB value in the forest fringe. Large trees dominate AGB, and our results showed the importance of medium-sized trees in compensating for the loss of large trees. This fragmented forest had fewer large trees than the primary forest due to anthropogenic disturbance (Bulafu et al. 2013), primarily the selective logging during plantation establishment.

Ordway and Asner (2020) reported a reduction of $22 \%$ AGB along forest peripheries extended $100 \mathrm{~m}$ into the forest interior due to changes in canopy structure.

\section{Species composition and diversity}

Among 274 tree species enumerated in all plots, Elateriospermum tapos is the most dominant species based on IVI value (80.0), followed by Santiria tomentosa (67.3) and Shorea macroptera (45.7). The top 10 dominant species according to IVI values are presented in Table 2. Elateriospermum tapos is abundant in the forest fringe and recorded in about $71 \%$ of our sampling plots. It also has the highest number of stems and basal all the tree species recorded. This species also accumulated the highest biomass with $20.8 \mathrm{Mg}$. This species was found in high abundance because it grows very well in forest core and secondary forests, kerangas forest, forest edges, and logging roads (Lim 2012).

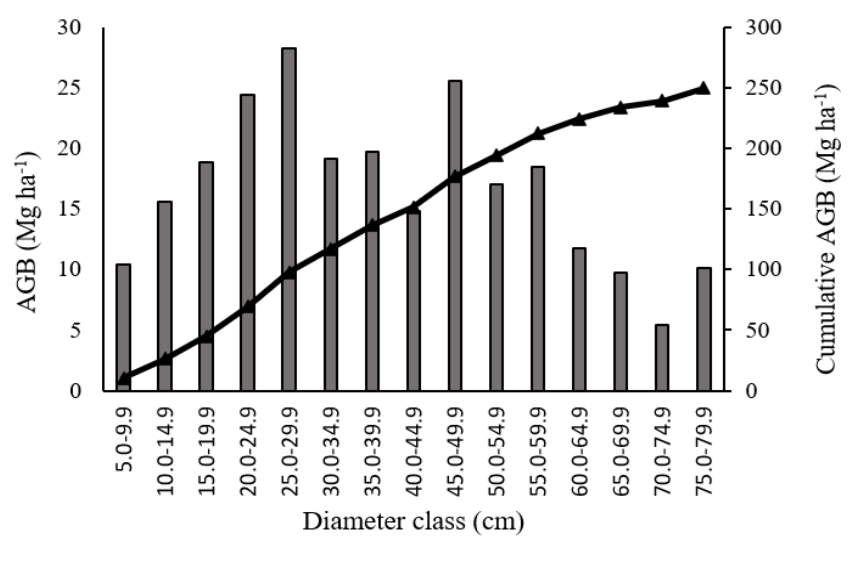

Figure 3. Aboveground biomass distribution (bars) among diameter class $(\mathrm{cm})$ with cumulative aboveground biomass on the second axis (line) for all trees species in the forest fringe 
Table 2. Top ten dominant species according to importance value at the forest fringe of a fragmented forest in an oil palm plantation

\begin{tabular}{|c|c|c|c|c|c|}
\hline Species & $\operatorname{Rba}(\%)$ & $\operatorname{Rf}(\%)$ & $\operatorname{Rd}(\%)$ & IVI (\%) & AGB (Mg) \\
\hline Elateriospermum tapos Blume & 5.1 & 70.8 & 4.1 & 80.0 & 20.1 \\
\hline Santiria tomentosa Blume & 2.4 & 62.5 & 2.4 & 67.3 & 6.3 \\
\hline Shorea macroptera Dyer & 2.7 & 41.7 & 1.4 & 45.7 & 7.8 \\
\hline Dryobalanops lanceolata Burck & 0.7 & 37.5 & 1.5 & 39.6 & 1.2 \\
\hline Litsea castanea Hook. f. & 0.5 & 37.5 & 1.2 & 39.2 & 0.7 \\
\hline Monocarpia marginalis (Scheff.) J. Sinclair & 0.8 & 33.3 & 0.9 & 35.1 & 1.5 \\
\hline Ficus geocharis Corner & 0.2 & 33.3 & 1.2 & 34.7 & 0.2 \\
\hline Palaquium ridleyi King \& Gamble & 1.2 & 29.2 & 2.0 & 32.4 & 3.3 \\
\hline Macaranga triloba (Thunb.) Müll.Arg. & 1.2 & 29.2 & 0.9 & 31.3 & 1.9 \\
\hline Artocarpus anisophyllus Miq. & 0.4 & 29.2 & 0.7 & 30.3 & 0.5 \\
\hline
\end{tabular}

Note: Rba: relative basal area; Rf: relative frequency; Rd: relative density; AGB: aboveground biomass. [One Megagram $(\mathrm{Mg})=1000 \mathrm{~kg}$ ]

Santiria tomentosa was abundant, with $62.5 \%$ of the samplings plots contain this species. The majority of its trees were in the range of 5 to $30 \mathrm{~cm}$ in DBH. In Sarawak, these species regenerate very well in logged-over forest, and it was the dominant species five years after logging, and it has some pioneer species features (Kochummen et al. 1995). However, it only accumulated $6.3 \mathrm{Mg}$ of biomass. Shorea macroptera is quite common in the forest fringe, with DBH mostly less than $20 \mathrm{~cm}$. It occurs in $41.7 \%$ of our sampling plots. At maturity, this tree species is a large and emergent tree growing up $50 \mathrm{~m}$ high and $150 \mathrm{~cm} \mathrm{DBH}$ (Soepadmo et al. 2002). This species accumulated the third-highest AGB at $7.8 \mathrm{Mg}$. In terms of AGB, the secondhighest was Shorea ovata with $\mathrm{AGB}$ at $12.0 \mathrm{Mg}$. The distribution of this tree species was scarce, but three large trees $(\mathrm{DBH}(\mathrm{cm}) 45.1,66.5,67.2)$ contributed $96 \%$ of its AGB. This shows that dominant species do not necessarily have a high AGB value, but it is the tree size that affects the value of AGB.

Out of 59 families, the top ten dominant tree families based on FIV is listed in Table 3. The top ten families contributed $63 \%$ and $70 \%$ of FIV and AGB values, respectively. The commonest families in the forest fringe were Dipterocarpaceae (50.2), Euphorbiaceae (32.6), and Lauraceae (22.7). In terms of AGB, the top three families were similar to FIV, where the highest ones were Dipterocarpaceae $(57.7 \mathrm{Mg})$, followed by Euphorbiaceae (33.7), and Lauraceae (17.7) (Table 3). Family Dipterocarpaceae recorded the highest number of trees (15.9\%), the richness species $(12.4 \%)$ and the largest basal area coverage $(21.8 \%)$ of families recorded in the forest fringe area.

There was a considerable contrast between Dipterocarpaceae and the rest of the families in tree density, species richness and basal area coverage, suggesting that species of dipterocarps can thrive in forest edges. Dipterocarps are generally shade-tolerant, but some species are light-demanding. Research has demonstrated that dipterocarps seedlings require more sunlight than the forest floor of a closed canopy forest for growth development (Brearley et al. 2017). For these reasons, forest fringe can support dipterocarp regeneration and growth as long as seeds disperse from mother trees within the forested areas.

\section{Diversity indices}

Species diversity between sampling plots showed slight variations. Shannon-Weiner index at 2.25 (Table 4) is considered high in terms of abundance and evenness of the species present. However, this is a low value compared to values reported by other studies in Malaysia. For instance, in a logged-over forest in Anap Muput, Bintulu, $H^{\prime}$ was 3.44 (Demies et al. 2019). Lambir Hills National Park lowland mixed dipterocarp forest recorded $H^{\prime}$ values of 4.1 to 4.3 (Takeuchi et al. 2017). In the lowland dipterocarp and riparian forests of Taman Negara Pahang, the $H$ ' values were 4.84 and 3.38, respectively (Zani et al. 2013). The $H^{\prime}$ values usually range from 1.5 to 3.5 but seldom reach 4.5 (Magurran 2004). Careful attention must be practiced when direct comparisons of indices are made because the values are affected by sample size and range of DBH measured for each study. Simpson's diversity index $(D)$ of the forest fringe was also high at 0.99 , indicating that tree species are rich and abundant. Species richness helps in carbon sequestration and promotes higher stand productivity (Liu et al. 2018).

Pielou's evenness index was small. The value of $E^{\prime}$ at 0.4 would suggest that the tree species was intermediately distributed. The species richness was computed using the Margalef index. From the 24 plots enumerated, the species richness was 39.80. The forest fringe is rich in species, as indicated by the Shannon-Weiner diversity index and Simpson's diversity index from the index value itself. The Margalef index must be cautious because it is highly sensitive to sample size (Magurran 2004). For a meaningful comparison, the total area sample should be as close as possible (Gamito 2010). Our calculated Morisita index was close to 0 (Table 4), indicating that the dispersion of tree species in the forest fringe is uniform. 
Table 3. Top ten dominant families based on family importance index at the forest fringe of a fragmented forest in an oil palm plantation.

\begin{tabular}{llllll}
\hline Species & RDe & RDi & Rbdo & FIV & $\begin{array}{l}\text { AGB } \\
\text { (Mg) }\end{array}$ \\
\hline Dipterocarpaceae & 15.9 & 12.4 & 21.8 & 50.2 & 57.5 \\
Euphorbiaceae & 12.3 & 7.664 & 12.6 & 32.6 & 33.7 \\
Lauraceae & 6.751 & 8.029 & 7.936 & 22.7 & 17.7 \\
Burseraceae & 6.435 & 3.285 & 5.964 & 15.7 & 14.8 \\
Moraceae & 4.219 & 4.380 & 5.309 & 13.9 & 13.6 \\
Annonaceae & 3.692 & 5.474 & 4.068 & 13.2 & 8.4 \\
Anacardiaceae & 3.270 & 3.650 & 5.456 & 12.4 & 14.6 \\
Myristicaceae & 4.325 & 4.745 & 2.506 & 11.6 & 4.2 \\
Melastomataceae & 3.797 & 2.190 & 2.600 & 8.587 & 4.9 \\
Sapotaceae & 4.114 & 2.190 & 2.195 & 8.499 & 4.9 \\
\hline Note: & &
\end{tabular}

Note: RDe: relative density; RDi: relative diversity; RbDo: relative dominance; FIV: family importance value, AGB: aboveground biomass.

Table 4. Tree diversity indices in the forest fringe of a fragmented forest in an oil palm plantation

\begin{tabular}{ll}
\hline Indices & Value \\
\hline Shannon-Weiner $\left(H^{\prime}\right)$ & 2.25 \\
Simpson index $(\mathrm{D})$ & 0.99 \\
Pielou's evenness $\left(E^{\prime}\right)$ & 0.40 \\
Margalef index $(\mathrm{d})$ & 39.80 \\
Morisita's index of dispersion & 0.03 \\
\hline
\end{tabular}

There is no doubt that this forest fringe has a high conservation value. It contributes to the HCV biodiversity through (i) the presence of species that flourish in the forest edge habitat, (ii) the high number of species composition, and (iii) the ability of some dipterocarp species adapted to edge conditions. The fringes are particularly vulnerable because they are indirectly affected by the introduction of weeds and alien plants or disturbance by mankind. The forest fringe should be protected and preserved to avoid destruction and alteration to the forest core habitat. The forest fringe structure and composition provide physical protection from wind and light, extreme weather, and other edge-related changes in microclimate.

This study showed that the forest edge environment affected the fringe community with the low basal area, tree density, large-diameter trees and AGB. However, the tree communities are considered rich and diverse. The tree species dispersion is uniform but unevenly distributed. The forest fringe communities are dominated by the family Dipterocarpaceae and Elateriospermum tapos, a species from the Euphorbiaceae family. The community structure is currently regenerating healthily. Generally, the forest fringe is similar in structure to the core forest. However, some major floristics differences between forest fringe and forest core are low in diversity and tree stocking. The number of large trees and AGB are also low in the forest fringe. The forest fringe structure and species composition must be maintained and free from human disturbance. The forest fringe is regenerating well and able to thrive in the forest edge environment. Thus, effective programs must be taken to protect and sustain biodiversity in fragmented forest areas.

\section{ACKNOWLEDGEMENTS}

We gratefully acknowledge Saremas Sdn. Bhd for their support and providing the necessary logistics and materials for this work. We wish to thank Mr James Wong Tai Hock, Mr Edward and his team for their assistance during the field sampling. We also would like to acknowledge the Faculty of Resource Science and Technology, University Malaysia Sarawak, for the support. This research was funded by PPB Oil Palms Berhad, a subsidiary company of Wilmar International Ltd. (GL/F07/WILMAR/03/2018).

\section{REFERENCES}

Amaral, MK, Netto, P, Lingnau, C, Filho, FA. 2015. Evaluation of the Morisita index for the determination of the spatial distribution of species in a fragment of Araucaria forest. Applied Ecology and Environmental Research 13(2): 361-372.

Aragón G, Abuja L, Belinchón R, Martínez S. 2015. Edge type determines the intensity of forest edge effect on epiphytic communities. Eur J Forest Res 134: 443-451. DOI: 10.1007/s10342-015-0863-5

Bakewell D, Donysius, M. 2014. Forest fragmentation in oil palm plantations: impacts on biodiversity and options for mitigation. Journal of Oil Palm, Environment \& Health. 5: 55-62. https://DOI: 10.5366/jope.2014.07

Brearley FQ, Banin LF, Saner P. 2016. The ecology of the Asian dipterocarps. Plant Ecol Divers 9 (5-6): 429-436. DOI: 10.1080/17550874.2017.1285363

Bulafu C, Barang D, Eycott AE, Mucunguzi P, Telford, RJ, Vandvik V. 2013. Structural Changes are More Important than Compositional Changes in Driving Biomass Loss in Ugandan Forest Fragments. Journal of Tropical Forestry and Environment. 3 (2): 23-38. DOI: $10.31357 /$ jtfe.v3i2.1840

Campbell MJ, Edward W, Magrach A, Alamgir M, Porolak G, Mohamdass D, Laurance, WF. 2018. Edge disturbance drives liana abundance increase and alteration of liana-host tree interactions in tropical forest fragments. Ecol Evol 8: 4237-4251. DOI: 10.1002/ece3.3959

Chave J, Andalo C, BrownS, Cairns MA, Chambers JQ, Eamus D, Folster H, Fromard F, Higuchi N, Kira T, Lescure JP, Nelson BW, Ogawa H, Puig H, Riera B, Yamakura T. 2005. Tree allometry and improved estimation of carbon stocks and balance in tropical forests. Oecologia 145: 87-99. DOI: 10.1007/s00442-005-0100-x

Ćosović M, Bugalho MN, Thom D, Borges JG. 2020. Stand Structural Characteristics Are the Most Practical Biodiversity Indicators for Forest Management Planning in Europe. Forests 11 (3): 343. DOI: 10.3390/f11030343

Dar JA, Subashree K, Raha D, Kumar A, Khare KP, Khan LM. 2019. Tree diversity, biomass and carbon storage in sacred groves of Central India. Environ Sci Pollut Res 26 (36): 37212-37227. DOI: 10.1007/s11356-019-06854-9

Demies M, Samejima H, Sayok AK, Noweg GT. 2019. Tree diversity, forest structure and species composition in a logged-over mixed dipterocarp, Bintulu, Sarawak, Malaysia. Transactions on Science and Technology 6 (1-2): 102-110.

Dong L, Zhang L, Li F. 2016. Developing two additive biomass equations for three coniferous plantation species in Northeast China. Forests 7 : $1-21$.

Dossa GGO, Paudel E, Fujinuma J, Yu H, Chutipong W. 2013. Factors determining forest diversity and biomass on tropical volcano, Mt. 
Rinjani, Lombok, Indonesia. PLoS ONE 8 (7): e67720. DOI: 10.1371/journal.pone.0067720

Feldpausch TR, Lloyd J, Lewis SL, Brienen RJWM, Gloor A, Mendoza AM, Lopez-Gonzalez G, Banin L, Abu Salim K, Affum Baffoe K, Alexiades M, Almeida S, Amaral I, Andrade A, Aragao LEOC, Murakami AA, Arets EJMM, Arroyo L, Aymard CGA, Baker TR, Banki OS, Berry NJ, Cardozo N, Chave J, Comiskey JA E, Alvarez E, Phillips OL. 2012. Tree height integrated into pantropical forest biomass estimates. Biogeosciences 9: 3381-3403. DOI: 10.5194/bg9-3381-2012

Gamito, S. 2010. Caution is needed when applying Margalef diversity index. Ecol Indic 10: 550-551.

Gebeyehu G, Soromessa T, Bekele T, Teketay D. 2019. Species composition, stand structure, and regeneration status of tree species in dry Afromontane forests of Awi Zone, northwestern Ethiopia. Ecosystem Health and Sustainability 5 (1): 199-215. DOI: 10.1080/20964129.2019.1664938.

Haddad NM, Lars A, Brudvig LA, Clobert J, Davies KF, Gonzalez A, Holt RD, Lovejoy TE. 2015. Habitat fragmentation and its lasting impact on Earth's ecosystems, Sci Adv 1(2): e1500052. DOI $10.1126 /$ sciadv 1500052

Hayes JJ, Castillo O. 2017. A new approach for interpreting the morisita index of aggregation through quadrat size. Int J Geoinf $6 \mathrm{~b}(10)$ : 1-15. DOI: $10.3390 /$ ijgi6100296

Jusoh I. 2017. Wood: Its benefits and versatility. Universiti Malaysia Sarawak. Kota Samarahan. [Malaysia]

Kacholi DS. 2014. Analysis of Structure and Diversity of the Kilengwe Forest in the Morogoro Region, Tanzania. International Journal of Biodiversity Article ID 516840. DOI: 10.1155/2014/516840

Khapugin AA. 2019. Benefits from visualization of environmental factor gradients: a case study in a protected area in central Russia. Revista Chapingo Serie Ciencias Forestales y del Ambiente 25 (3): 383-397. DOI: $10.5154 /$ r.rchscfa.2019.01.004

Kochummen KM. 1989. Lauraceae. Tree Flora of Malaya. Volume 4. Longman, Malaysia.

Lim TK. 2012. Elateriospermum tapos. Edible Medicinal And NonMedicinal Plants. Springer, Dordrecht. DOI: 10.1007/978-94-0071764-0_62

Letro L, Wangchuk S, Dhendup T. 2020. Distribution of Asiatic Black Bear and its interaction with humans in Jigme Singye Wangchuk National Park, Bhutan. Nature Conservation Research 5 (1): 44-55. DOI: $10.24189 /$ ncr.2020.004

Ling CY, Julia S. 2012. Diversity of the tree flora in Semenggoh Arboretum, Sarawak, Borneo. Gard Bull, Singapore. 64 (1): 139-169.

Liu X, Trogisch S, He JS, Niklaus PA, Bruelheide H, Tang Z, Erfmeier A, Scherer-Lorenzen M, Pietsch KA, Yang B, Kuhn P, Scholten T, Huang Y, Wang C, Staab M, Leppert KN, Wirth C, Schmid B, Ma K. 2018. Tree species richness increases ecosystem carbon storage in subtropical forests. Proc. R. Soc. B 285: 20181240. DOI $10.1098 / \mathrm{rspb} .2018 .1240$

Magurran AE. 2004. Measuring biological diversity. Blackwell Science Ltd.

Martinez-Camilo R, Gonzalez-Espinosa M, Ramirez-Marcial N, Cayuela L, Perez-Farrera MA. 2018. Tropical tree species diversity in a mountain system in southern Mexico: local and regional patterns and determinant factors. Biotropica 50(3): 499-509.

Mohd-Azlan J, Lok L, Maiwald MJ, Fazlin S, Shen TD, Kaicheen, SS, Dagang P. 2020. The distribution of medium large mammals in Samunsam Wildlife Sanctuary, Sarawak in Relation to the Newly constructed Pan-Borneo Highway. Nature Conservation Research 5 (4): 43-54. DOI: $10.24189 /$ ncr.2020.055
Moss I. 2012. Stand structure classification: A quantitative approach stand structure classification: A quantitative approach. [Ph.D. Dissertation]. The University British of Columbia.

Mullu D. 2016. A review on the effect of habitat fragmentation on ecosystem. J Nat Sci Res 6 (15): 1-15

Ordway EM, Asnber GP. (2020). Carbon declines along tropical forest edges correspond to heterogeneous effects on canopy structure and function. Proc Natl Acad Sci USA 117(14):7863-7870. DOI: 10.1073/pnas.1914420117

Pastorella F, Paletto A. 2013. Stand structure indices as tools to support forest management: an application in Trentino forests. J For Sci 59(4): 159-168. https://DOI: 10.17221/75/2012-JFS

Patrício MB, Ferreira JHD, do Couto EV. 2019. The context of the size and distance of Atlantic Forest fragments in a small city in Southern Brazil. Acta Scientiarum Biological Sciences 41: e46936. DOI: 10.4025/actascibiolsci.v41i1.46936

Perazza G, Decarli M. 2020. Monitoring of Cypripedium calceolus (Orchidaceae) in the Adamello-Brenta Natural Park (Italy). Nature Conservation Research. 5 (Suppl.1): 178-184. DOI: 10.24189/ncr.2020.045

Pontes DMFP, Engel VL, Parrotta JA. 2019. Forest Structure, wood standing stock, and tree biomass in different restoration systems in the Brazilian Atlantic forest. Forest 10 (7): 588. DOI: 10.3390/f10070588

Prospero S, Cleary M. 2017. Effects of host variability on the spread of invasive forest diseases. Forests 8 (3): 80. DOI: 10.3390/f8030080

Ravindranath NH, Ostwald M. 2018. Carbon Inventory Methods: Handbook for Greenhouse Gas Inventory, Carbon Mitigation and Roundwood Production Projects. Springer, Germany.

Shevade VS, Loboda TV. 2019. Oil palm plantations in Peninsular Malaysia: Determinants and constraints on expansion. PLoS ONE 14 (2): 1-22.

Simanov SA, Matantseva MV. 2020. Analysis of the current status of avifauna in Kostomuksha State Nature Reserve and Kalevala National Park (North-West Russia), taking into account influence from adjacent areas. Nature Conservation Research 5 (3): 51-65. DOI: 10.24189/ncr.2020.031

Slik JWF, Paoli G, McGuire K, Amaral I, Barroso J, Bastian M, Blanc L, Bongers F, Boundja P, Clark C, Collins M, Dauby G, Ding Y, Doucet JL, Eler E, Ferreira L, Forshed O, Fredriksson G, Gillet JF. 2013. Large trees drive forest aboveground biomass variation in moist lowland forests across the tropics. Global Ecol. Biogeogr 22 (12): 12261-1271. DOI: $10.1111 /$ geb.12092

Soepadmo E, Saw LG, Chung RCK. 2002. Tree flora of Sabah and Sarawak Vol $1-6$. Forest Research Institute Malaysia. Kuala Lumpur.

Takeuchi Y, Soda R, Diway B, Kuda T, Nakagawa M, Nagamasu H. 2017. Biodiversity conservation values of fragmented communally reserved forests, managed by indigenous people, in a human-modified landscape in Borneo. PLoS ONE 12 (11): e0187273. DOI: 10.1371/journal.pone. 0187273

Vieilledent G, Fischer FJ, Chave J, Guibal D, Langbour P, Gerard J. 2018. New formula and conversion factor to compute basic wood density of tree species using a global wood technology database. Am J Bot 105 (10): 1653-1661DOI: 10.1002/ajb2.1175

Vilma B, Demies M, Julia S, Unggang J. 2012. Tree Diversity in Mina Wildlife Corridor, Bintulu, Sarawak, Malaysia. International Symposium of Forestry \& Forest Products. 5-7 October 2010, Kuala Lumpur, Malaysia.

Zani NF, Suratman MN, Khalid F. 2013. Floristic Composition and Diversity in Lowland Dipterocarp and Riparian Forests of Taman Negara Pahang. The 2013 IEEE Symposium on Humanities, Science and Engineering Research (SHUSER 2013). 23-26 June 2013, Penang, Malaysia. 